\title{
Effect of strain rate on the hydrogen embrittlement of a DP steel
}

\author{
Tom Depover ${ }^{1, *}$, Ahmed Elmahdy ${ }^{2}$, Florian Vercruysse $^{2}$, Patricia Verleysen ${ }^{2}$, and Kim Verbeken ${ }^{1}$ \\ ${ }^{1}$ Department of Materials, Textiles and Chemical Engineering, Ghent University, 9052 Zwijnaarde, Belgium \\ ${ }^{2}$ EEMMeCs Department of Electrical Energy, MST-DyMaLab, Ghent University, 9052 Zwijnaarde, Belgium
}

\begin{abstract}
Advanced high strength steels (HSSs), such as dual phase steels, are widely used in the automotive industry due to their excellent combination of strength and ductility. In certain applications, they might be exposed to hydrogen $(\mathrm{H})$ which is known to be detrimental for the deformation. $\mathrm{H}$ embrittlement (HE) is still not fully understood. It might drastically reduce the energy absorbed in a crash event and limits the use of HSSs in car bodies. Although $\mathrm{H}$ diffusion is a highly time dependent phenomenon, so far, the combined effect of dynamic strain rates and electrochemical $\mathrm{H}$ pre-charging has not been studied. Therefore, a reproducible methodology has been developed. Tensile specimens were electrochemically $\mathrm{H}$ pre-charged and immediately tested in a split Hopkinson tensile bar setup. To distinguish between the effect of strain rate and HE, static tests have been conducted using the same procedure. Results show that the HE resistance decreased due to higher $\mathrm{H}$ amounts in the sample for all strain rates. The HE increased when slower strain rates were applied due to higher probability of $\mathrm{H}$ to diffuse to regions of stress concentration ahead of a crack tip and as such accelerating failure. At the highest strain rate considered $\left(900 \mathrm{~s}^{-1}\right)$, the material still lost about $10 \%$ of its ductility.
\end{abstract}

\section{Introduction}

In the automotive industry, advanced high strength steels (AHSs), such as dual phase (DP) steels, are widely used due to their outstanding combination of both formability and strength. The use of these AHSs has been stimulated since these materials can both guarantee an increased safety together with the weight reduction required to meet the rigorous $\mathrm{CO}_{2}$ emissions regulations. DP steel has a ferrite-martensite microstructure with low yield strength, but a high work hardening exponent at low and moderate deformation levels leading to a high ultimate tensile strength. Although the mechanical properties of AHSs are excellent, they are unfortunately considered to be prone to hydrogen $(\mathrm{H})$ induced mechanical degradation. Moreover, further alloy development of AHSs has been reported to be hindered by the $\mathrm{H}$ phenomenon [1]. Essentially, in the presence of $H$, these materials undergo a large ductility loss, mainly referred to as hydrogen embrittlement (HE). Amongst others, DP, transformation induced plasticity (TRIP) and high strength low alloyed (HSLA) steels are widely used grades in the automotive industry and were therefore already subject of numerous $\mathrm{H}$ related research [2-7].

AHSs are often used in body-in-white vehicle structures due to their weight reducing capacity and increased safety guarantee. Crashworthiness is a key parameter of their applicability and many mechanical parameters are strain rate dependent. Therefore, the effect of strain rate on hardening and fracture of AHSs has been studied extensively. However, the combination of $\mathrm{H}$ induced mechanical degradation and dynamic high strain rate conditions have not been given much attention so far. Therefore, the aim of this work is to investigate the effect of $\mathrm{H}$ on the impact properties of a specific DP steel grade. This $\mathrm{H}$ influence was evaluated by modifying both the $\mathrm{H}$ content in the tensile specimens and the applied strain rate going from static to dynamic conditions.

\section{Experimental procedure}

\subsection{Material characterization}

The sensitivity of a DP600 steel to $\mathrm{H}$ induced mechanical degradation was investigated in this work. Hot and cold rolling was done till a final thickness of 1.2 $\mathrm{mm}$, which was followed by subsequent annealing via industrial annealing parameters required to attain the desired microstructure. The chemical composition is presented in Table 1. The DP600 steel is a ferriticmartensitic dual phase steel with approximately $23.6 \%$ of martensite. The corresponding grain sizes were about $7 \mu \mathrm{m}$ for the ferritic phase and about $2 \mu \mathrm{m}$ for the martensitic phase, as shown in Fig. 1.

Tensile samples were machined with their tensile axis parallel to the rolling direction. A dogbone-shaped specimen geometry was used, as illustrated in Fig. 2. The small size of the samples is required for the dynamic tests [8]. However, in order to exclude effects related to sample geometry, the same sample geometry is used for the static tests as well.

\subsection{The hydrogen/material interaction}

Corresponding author: tom.depover@ugent.be 
The total amount of $\mathrm{H}$ was determined by melt extraction at $1600{ }^{\circ} \mathrm{C}$. Samples were charged with $\mathrm{H}$ electrochemically in $1 \mathrm{~g} / \mathrm{l}$ thiourea $0.5 \mathrm{M} \mathrm{H}_{2} \mathrm{SO}_{4}$ electrolyte for two hours, which guaranteed saturation without $\mathrm{H}$ induced damage, as shown in [9]. The applied current density was modified to induce different amounts of $\mathrm{H}$ into the tensile samples. For absorption from an aqueous solution, a relation is found between $\mathrm{H}$ solubility and applied current density during electrochemical charging, i.e. the $\mathrm{H}$ solubility is proportional to the square root of the current density [10]. Therefore, the applied current densities were increased from $0.8-5-25 \mathrm{~mA} / \mathrm{cm}^{2}$. The time between $\mathrm{H}$ charging and $\mathrm{H}$ detection by melt extraction was kept constant at 2 minutes due to the experimental developed procedure to perform both the static and dynamic tensile tests, which also required 2 minutes between $\mathrm{H}$ charging and tensile testing. Hence, the amount of $\mathrm{H}$ present in the sample when the tensile test starts, is determined.

Table 1. Chemical composition of DP steel in $\mathrm{wt} \%$.

\begin{tabular}{|c|c|c|c|c|}
\hline wt(\%) & C & Mn & Si & Other \\
\hline & 0.07 & 1.50 & 0.25 & $0.4 \%-0.8 \% \mathrm{Cr}+\mathrm{Mo}$ \\
\hline
\end{tabular}

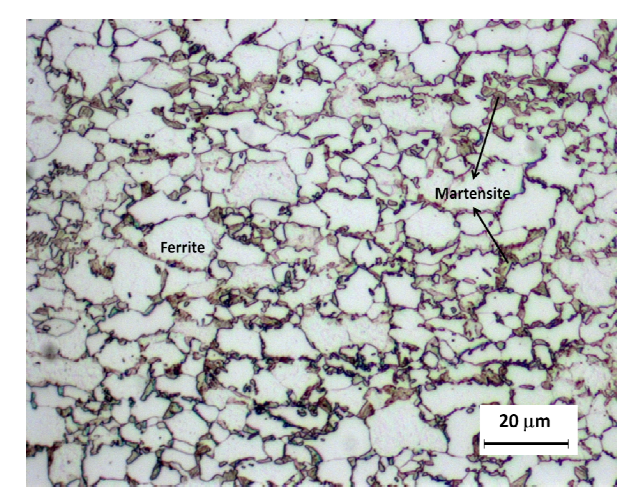

Fig. 1. Light optical microscopic image of DP600 steel.



Fig. 2. Geometry of the tensile specimens (in $\mathrm{mm}$ ).

The degree of HE was verified by performing tensile tests on both uncharged and $\mathrm{H}$ charged samples while using the abovementioned $\mathrm{H}$ charging parameters. The $\mathrm{H}$ impact was quantified by the $\mathrm{HE} \%$, as defined in Eq. (1), with $\varepsilon_{\mathrm{ch}}$ and $\varepsilon_{\mathrm{un}}$ being the engineering strains at fracture averaged over the sample gauge section of the $\mathrm{H}$ charged and uncharged sample, respectively. Hence, the HE degree can vary between 0 and 1 , with 0 indicating no ductility drop and insensitivity to HE. When an index of 1 is obtained, the ductility drop is $100 \%$ and the HE is maximal.

$$
\% H E=100\left(1-\frac{\varepsilon_{\mathrm{ch}}}{\varepsilon_{\mathrm{un}}}\right)
$$

Initially, the HE sensitivity was studied by static tensile tests performed on both uncharged and $\mathrm{H}$ charged specimens using a standardized Instron tensile machine.

$\mathrm{H}$ charging was done for two hours and tensile tests were executed ex-situ due to experimental requirements. A constant time lag of 2 minutes between $\mathrm{H}$ charging and tensile testing was maintained. The observations were correlated with those obtained by the melt extraction, which was also done 2 minutes after $\mathrm{H}$ charging. In a first series of static tests, the impact of the $\mathrm{H}$ content on the HE susceptibility was evaluated by using samples which were $\mathrm{H}$ charged at different applied current densities. Secondly, the effect of $\mathrm{H}$ diffusivity was verified by considering two different -though still static- strain rates: 0.0167 and $1.67 \mathrm{~s}^{-1}$.

Additionally, the strain rate was further increased till dynamic conditions. These high strain rate tests were done on a split Hopkinson tensile bar (SHTB) setup [11, 12]. For this purpose, the specimen was pinned into slots between two long bars, the input and output bar. The impact of a projectile generates a tensile loading wave at the free end of the input bar which propagates along the input bar towards the sample where it interacts with the specimen resulting in a high strain rate tensile loading of the sample. The loading wave is partly reflected back to the input bar and partly transmitted towards the output bar. Strain gauges on the bars measure the strain corresponding with the loading, reflected and transmitted waves. From those waves, the total force and elongation history of the tensile sample can be determined based on the principles of 1-dimensional elastic-wave propagation in bars [13]. The dynamic tests were done at average strain rates of \pm 450 and $\pm 900 \mathrm{~s}^{-1}$.

As such, the effect of $\mathrm{H}$ can be elucidated at crash impact velocities and the impact of $\mathrm{H}$ diffusivity can be analyzed on the fracture mode. High speed camera (HSC) images of the deforming sample were taken during the tests to capture fracture initiation and evaluate the fracture mode upon the applied strain rate.

\section{Results and discussion}

\subsection{Hydrogen induced mechanical degradation}

Melt extraction was done to determine the total $\mathrm{H}$ content, for which $\mathrm{H}$ charging was performed as described above. Different current densities were applied and the amount of $\mathrm{H}$ increased with applied current density (cf. Table 2), which was observed elsewhere as well [14]. The tensile specimens were charged with $\mathrm{H}$ under identical conditions. Hence, the actual amount of $\mathrm{H}$ present in the sample is known when the tensile test started.

\subsubsection{Tensile tests done under static conditions}


Tensile tests were performed on uncharged and $\mathrm{H}$ charged samples at current densities of $0.8,5$ and 25 $\mathrm{mA} / \mathrm{cm}^{2}$. The corresponding stress-strain curves of the tests done at strain rates of 0.0167 and $1.67 \mathrm{~s}^{-1}$ are, respectively, presented in Fig. 3 and Fig. 4. The degree of $\mathrm{HE}$ was determined and summarized for all conditions in Table 3. Generally, the sensitivity to HE increases with higher applied current density, which can be attributed to the increased $\mathrm{H}$ content (cf. Table 2) [15]. This corresponds to previous obtained results and confirms the correlation between the HE susceptibility and the $\mathrm{H}$ amount present in the sample [16-19].

Table 2. Total amount of hydrogen determined by melt extraction for different applied current densities.

\begin{tabular}{|c|c|c|c|c|}
\hline H content & Air & $\begin{array}{c}\mathbf{0 . 8} \\
\mathbf{m A} / \mathbf{c m}^{\mathbf{2}}\end{array}$ & $\begin{array}{c}\mathbf{5} \\
\mathbf{m A} / \mathbf{c m}^{\mathbf{2}}\end{array}$ & $\begin{array}{c}\mathbf{2 5} \\
\mathbf{m A} / \mathbf{c m}^{2}\end{array}$ \\
\hline wppm & 0.52 & 3.77 & 4.67 & 4.97 \\
\hline
\end{tabular}

Furthermore, the HE resistance increased when a higher strain rate was applied. This was correlated to the $\mathrm{H}$ diffusion distance which decreases with higher testing speed, as described in $[9,19]$. The distance $x(\mathrm{~cm})$ over which $\mathrm{H}$ can diffuse, can be calculated by taking the square root of the product of the diffusion coefficient $D$ $\left(\mathrm{cm}^{2} / \mathrm{s}\right)$ and the time $t(\mathrm{~s})$ of the tensile test, i.e. $x=(D \mathrm{x}$ $t)^{1 / 2}[19,20]$. Therefore, during a test performed at strain rate of $0.0167 \mathrm{~s}^{-1}$, from the onset of deformation till fracture, $\mathrm{H}$ was able to diffuse over approximately 30 $\mu \mathrm{m}$, whereas at $1.67 \mathrm{~s}^{-1}, \mathrm{H}$ was just able to diffuse over about $3 \mu \mathrm{m}$. Towards the end of the tensile tests, a crack is formed. Close to the crack tip, a zone characterized by a stress concentration is generated. $\mathrm{H}$ can diffuse to this zone and hence accelerate the $\mathrm{H}$ induced failure. When the applied strain rate was increased, $\mathrm{H}$ showed a smaller potential to assist the failure process since the distance it can diffuse during the fracture process is limited.

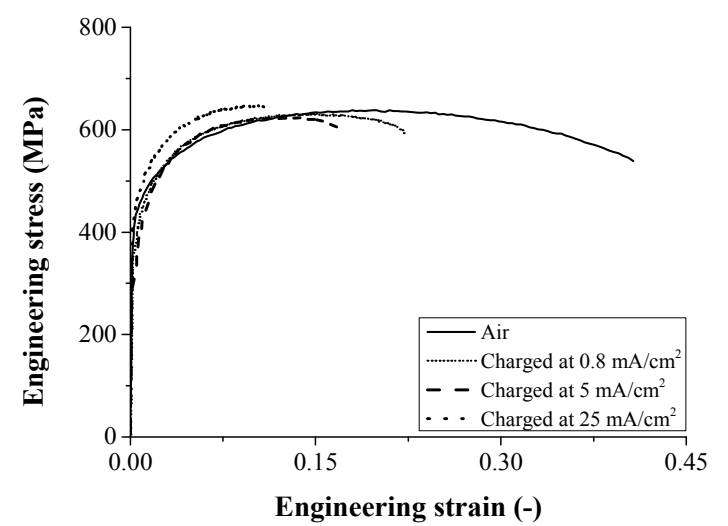

Fig. 3. Engineering stress-strain diagrams of static tensile tests done at strain rate of $0.0167 \mathrm{~s}^{-1}$.

The fracture initiation in the static tensile tests was studied in detail. The initiation of failure was captured by HSC and a sequence of the images, just before fracture of the tensile test, were further analysed. The corresponding images of the test performed at a strain rate of $1.67 \mathrm{~s}^{-1}$ on an uncharged sample are presented in Fig. 5. Considerable diffuse necking can be observed.
Moreover, the final fracture initiation was located at the center of the specimen, indicating a ductile failure mode affected by the high stress triaxiality in the center of the tensile sample.

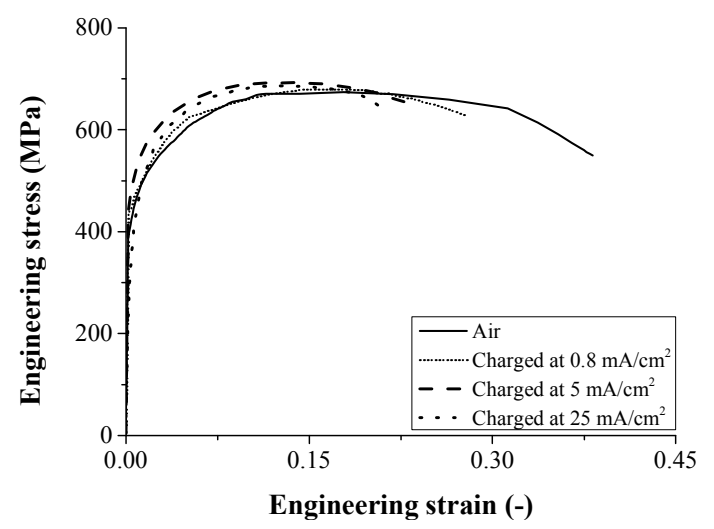

Fig. 4. Engineering stress-strain diagrams of static tensile tests performed at a strain rate of $1.67 \mathrm{~s}^{-1}$.

Table 3. Summary of the degrees of $\mathrm{H}$ induced mechanical degradation.

\begin{tabular}{|l|c|c|c|}
\hline $\mathbf{H E} \%$ & $\begin{array}{c}\mathbf{0 . 8} \\
\mathbf{m A} / \mathbf{c m}^{\mathbf{2}}\end{array}$ & $\begin{array}{c}\mathbf{5} \\
\mathbf{m A} / \mathbf{c m}^{\mathbf{2}}\end{array}$ & $\begin{array}{c}\mathbf{2 5} \\
\mathbf{m A} / \mathbf{c m}^{\mathbf{2}}\end{array}$ \\
\hline $\mathbf{0 . 0 1 6 7} \mathbf{s}^{-1}$ & 45 & 58 & 72 \\
\hline $\mathbf{1 . 6 7} \mathbf{s}^{-1}$ & 27 & 37 & 45 \\
\hline
\end{tabular}

The failure sequence of the $\mathrm{H}$ charged (at current density of $5 \mathrm{~mA} / \mathrm{cm}^{2}$ ) specimen tested at $0.0167 \mathrm{~s}^{-1}$ is shown in Fig. 6. As opposed to the uncharged sample, localized necking occurred and the final fracture initiated at the edge of the sample. This was attributed to the damaging effect of $\mathrm{H}$ on the material at the sample edge where lattice $\mathrm{H}$ preferentially diffuses to. Therefore, this $\mathrm{H}$ is able to embrittle the material locally, leading to failure initiation and a further accelerated fracture propagation from the edge onwards. These findings were also observed for in-situ $\mathrm{H}$ charged tensile specimens of DP and TRIP steel $[4,5,9]$, on which $\mathrm{H}$ induced failure initiation and propagation was evaluated by electron backscattered diffraction and scanning electron microscopy analysis.

Nevertheless, a different failure mode was observed when the strain rate was increased to $1.67 \mathrm{~s}^{-1}$ after $\mathrm{H}$ charging at $0.8 \mathrm{~mA} / \mathrm{cm}^{2}$, as illustrated in Fig. 7. The corresponding fracture initiation occurred clearly in the center of the tensile specimen, similarly to the tensile tests performed on uncharged material (cf. Fig. 5). Basically, the fracture initiation occurred in the centre for all the tests performed in the uncharged condition at both strain rates, whereas only the $\mathrm{H}$ charged samples tested at the higher strain rate of $1.67 \mathrm{~s}^{-1}$ showed fracture initiation in the centre. An overview of the fracture initiation point for all tests is summarized in Table 4 .

A transition of fracture initiation from the edge to the centre was observed as a function of strain rate for $\mathrm{H}$ charged samples. Therefore, this transition in fracture mode, when the strain rate was increased, can be correlated with a decrease in $\mathrm{H}$ diffusion time and consequently the $\mathrm{H}$ diffusion distance $x$. Zones which are 
characterized by a stress concentrations ahead of a growing crack tip attract $\mathrm{H}$ from the neighbouring $\mathrm{H}$ saturated matrix, which probability to occur is increased at the slower strain rate. The brittle to ductile transition was observed between the strain rates of $0.0167 \mathrm{~s}^{-1}$ and $1.67 \mathrm{~s}^{-1}$, which is correlated to diffusion distances of about 30 and $3 \mu \mathrm{m}$, respectively.

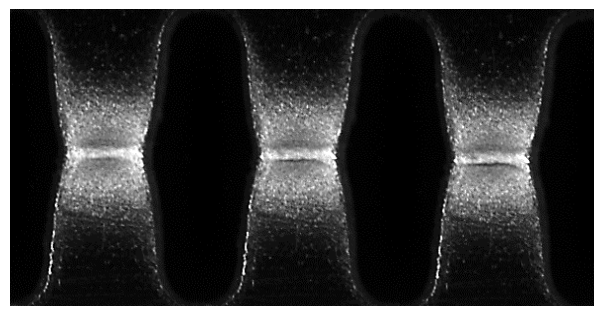

Fig. 5. HSC images of tensile test performed in air at strain rate of $1.67 \mathrm{~s}^{-1}$ during fracture.

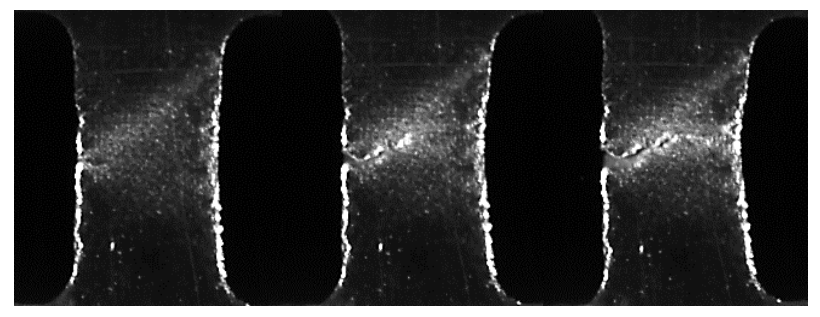

Fig. 6. HSC images of tensile test performed after $\mathrm{H}$ charging $\left(5 \mathrm{~mA} / \mathrm{cm}^{2}\right)$ at strain rate of $0.0167 \mathrm{~s}^{-1}$ during fracture.



Fig. 7. HSC images of tensile test performed after $\mathrm{H}$ charging $\left(0.8 \mathrm{~mA} / \mathrm{cm}^{2}\right)$ at strain rate of $1.67 \mathrm{~s}^{-1}$ during fracture.

Table 4. Overview of fracture modes in the static tensile. tests.

\begin{tabular}{|l|c|c|c|c|}
\hline $\begin{array}{l}\text { Fracture } \\
\text { initiation }\end{array}$ & Air & $\begin{array}{c}\mathbf{0 . 8} \\
\mathbf{m A} / \mathbf{c m}^{\mathbf{2}}\end{array}$ & $\begin{array}{c}\mathbf{5} \\
\mathbf{m A} / \mathbf{c m}^{\mathbf{2}}\end{array}$ & $\begin{array}{c}\mathbf{2 5} \\
\mathbf{m A} / \mathbf{c m}^{\mathbf{2}}\end{array}$ \\
\hline $\mathbf{0 . 0 1 6 7} \mathbf{s}^{-1}$ & Center & Edge & Edge & Edge \\
\hline $\mathbf{1 . 6 7} \mathbf{s}^{-1}$ & Center & Center & Center & Center \\
\hline
\end{tabular}

\subsubsection{Tensile tests done under dynamic conditions}

Tensile tests were also performed on uncharged and $\mathrm{H}$ charged samples at current densities of $0.8,5$ and 25 $\mathrm{mA} / \mathrm{cm}^{2}$ at dynamic conditions. The corresponding stress-strain diagrams of SHTB tests performed at a strain rate of 450 and $900 \mathrm{~s}^{-1}$ are displayed in Fig. 8 and Fig. 9, respectively. The resultant degrees of $\mathrm{HE}$ are given in Table 5. Even in these dynamic conditions, a clear impact of $\mathrm{H}$ on the mechanical properties was observed, i.e. the ductility dropped with about $10 \%$. In agreement to the static tests, the sensitivity to $\mathrm{H}$ induced mechanical degradation increased slightly with higher current densities, confirming the link between the HE\% and the amount of $\mathrm{H}$ content [15-18]. Moreover, a slightly lower degree of $\mathrm{HE}$ was obtained when the strain rate was increased. However, linking this observation to the diffusion distance $x$, over which $\mathrm{H}$ can diffuse during the tensile test, is not appropriate as the estimated $\mathrm{H}$ diffusion distances during the entire test were about 0.17 and $0.23 \mu \mathrm{m}$ at strain rates of 900 and $450 \mathrm{~s}^{-1}$, respectively.

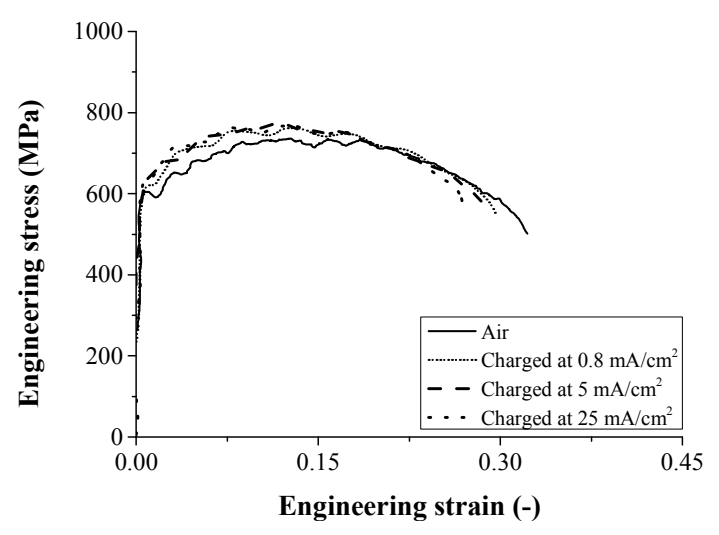

Fig. 8. Engineering stress-strain diagrams of dynamic SHTB tests done at a strain rate of $450 \mathrm{~s}^{-1}$.

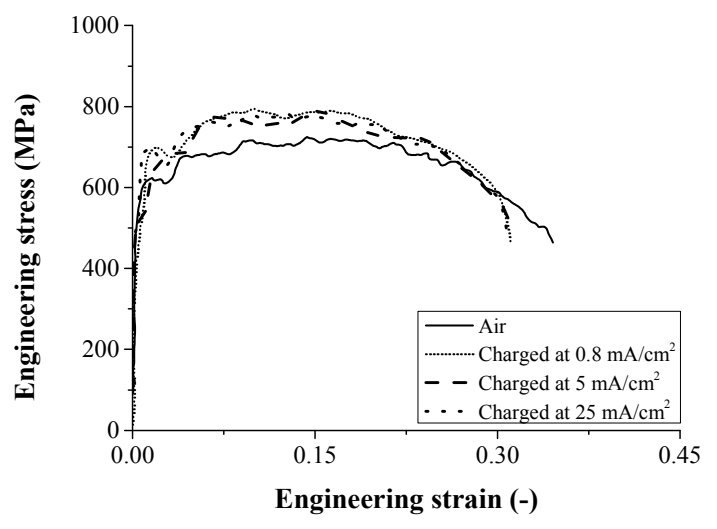

Fig. 9. Engineering stress-strain diagrams of dynamic SHTB tests done at a strain rate of $900 \mathrm{~s}^{-1}$.

Table 5. Summary of the HE\% for the dynamic tensile test conditions.

\begin{tabular}{|l|c|c|c|}
\hline $\mathbf{H E} \%$ & $\mathbf{0 . 8} \mathbf{~ m A} / \mathbf{c m}^{\mathbf{2}}$ & $\mathbf{5} \mathbf{~ m A} / \mathbf{c m}^{\mathbf{2}}$ & $\mathbf{2 5} \mathbf{~ m A} / \mathbf{c m}^{\mathbf{2}}$ \\
\hline $\mathbf{4 5 0} \mathbf{s}^{-1}$ & 9 & 11 & 16 \\
\hline $\mathbf{9 0 0} \mathbf{s}^{-1}$ & 8 & 9 & 11 \\
\hline
\end{tabular}

The fracture initiation during the dynamic tensile tests was again captured by HSC and the image sequence, just before fracture, was considered. The specimen tested after $\mathrm{H}$ charging at $25 \mathrm{~mA} / \mathrm{cm}^{2}$ at a strain rate of $450 \mathrm{~s}^{-1}$ is presented in Fig. 10. Fracture initiation was found to occur in the centre of the specimen. This is in agreement with the findings demonstrated before (cf. Table 4).

Generally, fracture initiation occurred in the centre for all the tests performed in the uncharged condition and for the $\mathrm{H}$ charged samples tested at the higher strain rate of $1.67 \mathrm{~s}^{-1}$. Since dynamic conditions were applied, failure initiation from the centre was expected to occur since the brittle to ductile transition of fracture initiation 
was observed as a function of strain rate for $\mathrm{H}$ charged samples.

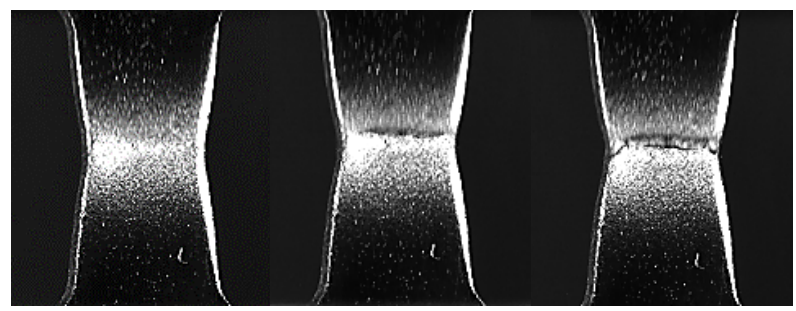

Fig. 10. HSC images of tensile test performed after $\mathrm{H}$ charging $\left(25 \mathrm{~mA} / \mathrm{cm}^{2}\right)$ at strain rate of $450 \mathrm{~s}^{-1}$ during fracture.

\subsection{SEM analysis of the fractography}

The fracture surfaces of the tensile specimens were analyzed by scanning electron microscopy and a ductile dimple pattern was generally observed. However, a thin brittle zone was present at the center of the sample which is correlated to the segregation line typical for DP steels, as demonstrated elsewhere $[9,21]$. The fracture surface of the uncharged and $\mathrm{H}$ charged sample at $25 \mathrm{~mA} / \mathrm{cm}^{2}$, both tensile tested at $1.67 \mathrm{~s}^{-1}$, is presented in Fig. 11 and Fig. 12, respectively. Comparison between both fracture surfaces showed a delamination in the central region for the $\mathrm{H}$ charged sample.

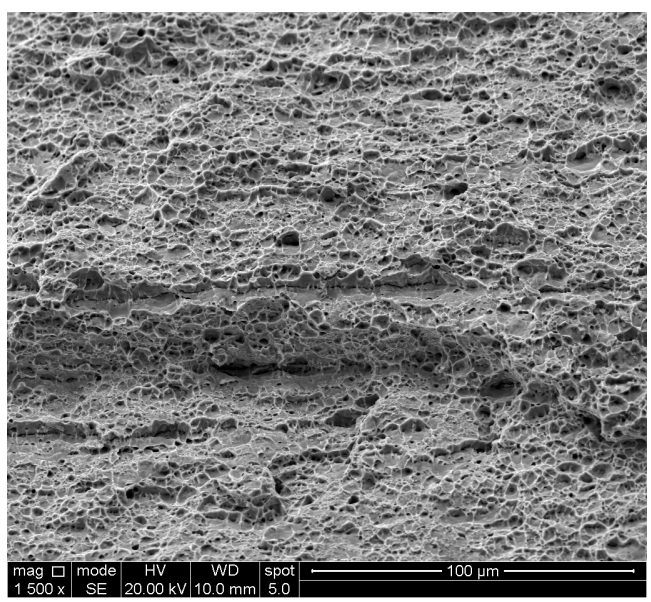

Fig. 11. SEM images of fracture surface of the uncharged specimen, tensile tested at $1.67 \mathrm{~s}^{-1}$.

Furthermore, the fracture surfaces of two dynamic tests at $450 \mathrm{~s}^{-1}$ and $\mathrm{H}$ charged at 0.8 and $25 \mathrm{~mA} / \mathrm{cm}^{2}$ are presented in Fig. 13 and Fig. 14, respectively. A central crack perpendicular to the fracture surface can again be observed. Its size increased with increased current density, i.e. it is linked to the higher $\mathrm{H}$ content. The brittle zone around the crack exhibited some shear characteristics. The crack width also increased slightly with increasing strain rate.

Fig. 15 shows a detailed characterization of the central delamination crack in the fracture surface of the tensile test performed at $900 \mathrm{~s}^{-1}$ after $\mathrm{H}$ charging at 5 $\mathrm{mA} / \mathrm{cm}^{2}$. Second phase particles were observed and EDX analysis revealed the presence of $\mathrm{MnS}$ inclusions, which are known to be harmful for $\operatorname{HE}[9,21]$. When the fracture surfaces of the static and dynamic tensile tests are compared, similar conclusions can be drawn: a dimpled, ductile fracture surface with brittle features at the $\mathrm{MnS}$ containing central segregation line. However, no extensive delamination crack was present for the static tests, while a clear crack propagating throughout the sample centre was detected for the dynamic tests.



Fig. 12. SEM images of fracture surface of the specimen $\mathrm{H}$ charged at $25 \mathrm{~mA} / \mathrm{cm}^{2}$ (right), tensile tested at $1.67 \mathrm{~s}^{-1}$.



Fig. 13. SEM images of fracture surface of specimen $\mathrm{H}$ charged at $0.8 \mathrm{~mA} / \mathrm{cm}^{2}$, tensile tested at $450 \mathrm{~s}^{-1}$.

\section{Conclusion}

Tensile tests under static and dynamic conditions were performed to evaluate the $\mathrm{H}$ induced mechanical degradation in DP steel. The samples were $\mathrm{H}$ charged till saturation and tensile tests were subsequently done exsitu. The applied current density was modified to introduce different amount of $\mathrm{H}$ into the tensile specimens. The effect of the $\mathrm{H}$ diffusivity during the tensile test on the HE susceptibility was estimated by increasing the strain rate from static $\left(1.67 * 10^{-2}\right.$ and 1.67 $\mathrm{s}^{-1}$ ) to dynamic (450 and $\left.900 \mathrm{~s}^{-1}\right)$ conditions.

The HE sensitivity increased with applied current density due to higher amounts of induced $H$, as determined by melt extraction. Moreover, the degree of HE was increased when slower strain rates were applied. This was linked to higher probability of $\mathrm{H}$ to diffuse to regions of stress concentration ahead of a crack tip at slower strain rate and, as such, accelerating failure. Even at the highest strain rate of $900 \mathrm{~s}^{-1}$, the material lost 
about $10 \%$ of its ductility, which was related with $\mathrm{H}$ present in the samples and not due to $\mathrm{H}$ diffusion during testing. This was concluded since $\mathrm{H}$ induced failure initiated at the edges of the samples at slow strain rates. However, at a strain rate of $1.67 \mathrm{~s}^{-1}$, fracture initiated in a ductile way from the centre similarly as in the tests performed in air.
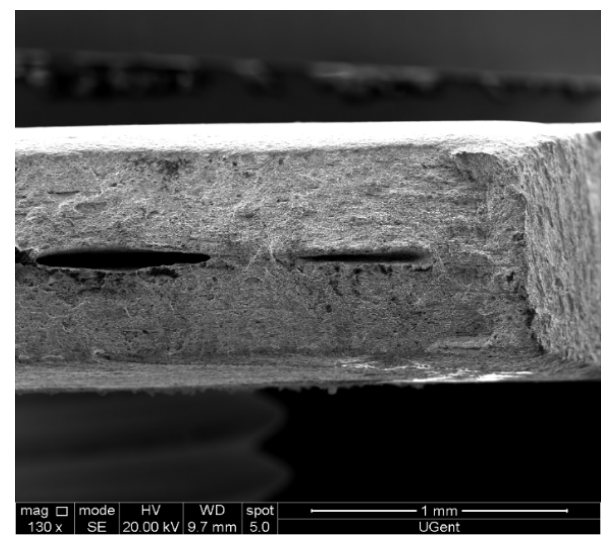

Fig. 14. SEM images of fracture surface of specimen $\mathrm{H}$ charged at $25 \mathrm{~mA} / \mathrm{cm}^{2}$, tensile tested at $450 \mathrm{~s}^{-1}$.



Fig. 15. MnS inclusions in the $\mathrm{H}$ induced crack observed in the central segregation line on the fracture surface of the specimen $\mathrm{H}$ charged at $5 \mathrm{~mA} / \mathrm{cm}^{2}$, tensile tested at $900 \mathrm{~s}^{-1}$, as revealed by EDX analysis.

Fractographic analysis demonstrated a brittle central line when $\mathrm{H}$ charged, which evolved into a major crack which size increased with applied strain rate. EDX analysis revealed the presence of $\mathrm{MnS}$ inclusions in this segregation line, initiating the $\mathrm{H}$ induced cracks.
Tom Depover holds a postdoctoral fellowship via grant $\mathrm{nr}$. BOF01P03516. The authors wish to thank the Special Research Fund (BOF), U. Gent (BOF15/BAS/06). The authors also acknowledge the technical staff from the Department Materials, Textiles and Chemical Engineering and the Department of Electrical Energy, Metals, Mechanical Constructions \& Systems, U. Gent, for their help with experiments and/or sample preparation.

\section{References}

1. M. Loidl, O. Kolk, Adv. Mat. and Proc., 169, 22, BMW Group, Germany (2011)

2. J.H. Ryu, Y.S. Chun, C.S Lee, H.K.D.H. Bhadeshia, D.W. Suh, Acta Mat., 60, 4085 (2012)

3. J. Sun, T. Jiang, Y. Sun, Y. Wang, Y. Liu, Journal of Alloys and Compounds, 698, 390 (2017)

4. A. Laureys, T. Depover, R. Petrov, K. Verbeken, Int Journal of H Energy, 40, 16901 (2015)

5. A. Laureys, T. Depover, R. Petrov, K. Verbeken, Mat. Char., 112, 169 (2016)

6. Q. Liu, J. Venezuela, M. Zhang, Q. Zhou, A. Atrens, Corrosion Science, 111770 (2016)

7. J.A. Ronevich, J.G. Speer, D.K. Matlock, SAE Int Journal Mat. Man., 3255 (2010)

8. P. Verleysen, J. Degrieck, T. Verstraete, J. Van Slycken, Exp. Mech., 48, 587 (2008)

9. T. Depover, E. Wallaert, K. Verbeken, Mat. Sci. and Eng. A, 649, 201 (2016)

10. R.N. Iyer, H.W. Pickering, M. Zamanzadeh, Journal of Electrochemical Soc., 136, 2463 (1989)

11. P. Verleysen, J. Degrieck, Int Journal of Impact Eng., 38, 406 (2011)

12. J. Van Slycken, P. Verleysen, J. Degrieck, J. Bouquerel, B.C. De Cooman, Mat. Sci. and Eng. A, 460, 516 (2007)

13. H. Kolsky, Proc. Phys. Soc. London B, 62, 676 (1949)

14. Q. Liu, A.D. Atrens, Z. Shi, K. Verbeken, A. Atrens, Corrosion Science, 87, 239 (2014).

15. T. Depover, K. Verbeken, Corrosion Science, 112, 308 (2016)

16. T. Depover, K. Verbeken, Mat. Sci. and Eng. A, 669, 134, (2016)

17. T. Depover, K. Verbeken, Int Journal of H Energy, 41, 14310 (2016)

18. T. Depover, K. Verbeken, Mat. Sci. and Eng. A, 675, 299 (2016)

19. T. Depover, K. Verbeken, Mat. Sci. and Eng. A, 664, 195 (2016)

20. M. Koyama, C.C. Tasan, E. Akiyama, K. Tsuzaki, D. Raabe, Acta Mat., 70, 174 (2014)

21. D. Pérez Escobar, C. Miñambres, L. Duprez, K. Verbeken, M. Verhaege, Corrosion Science, 53, 3166 (2011) 